\title{
Anatomía foliar comparada y sistemática del clado-Trichocentrum con énfasis en Cohniella (Asparagales: Orchidaceae)
}

\author{
William Cetzal-Ix ${ }^{1}$, Eliana Noguera-Savelli ${ }^{2}$, Damelis Jáuregui ${ }^{3}$ \& Germán Carnevali ${ }^{4}$
}

1. El Colegio de la Frontera Sur, Unidad Chetumal, Av. del Centenario, km 5.5, Chetumal, Quintana Roo 77000, México; rolito22@hotmail.com

2. El Colegio de la Frontera Sur, División de Conservación de la Biodiversidad, Departamento de Ecología y Sistemática Terrestre, San Cristóbal de Las Casas 29290, Chiapas, México; eliananoguera@gmail.com

3. Instituto de Botánica Agrícola, Facultad de Agronomía. Universidad Central de Venezuela. Apartado postal 4579, Maracay 2101, Aragua, Venezuela; jaureguid@gmail.com

4. Herbario CICY, Centro de Investigación Científica de Yucatán, A. C. (CICY), Calle 43. No. 130. Col. Chuburná de Hidalgo, Mérida 97200, Yucatán, México; carneval@cicy.mx

Recibido 24-I-2013. Corregido 20-VI-2013. Aceptado 22-VII-2013.

\begin{abstract}
Comparative foliar anatomy and systematics of the Trichocentrum-clade with emphasis in Cohniella (Asparagales: Orchidaceae). The genera Cohniella, Lophiarella, Lophiaris, and Trichocentrum are included in the Trichocentrum-clade. These genera are distributed from Florida and Northern Mexico to Southern Brazil and Northern Argentina, growing in tropical deciduous forests or tropical rain forests and thorn scrub forests to pine-oak forest, from sea level to $1700 \mathrm{~m}$. The leaf anatomical structure of 23 members of the Trichocentrum-clade was explored as a source of taxonomic and phylogenetic characters. A total of 11 species of Cohniella, three species of Lophiarella, seven species of Lophiaris, two species of Trichocentrum, and other four species were included as outgroup. Anatomical characters were studied by cross sections and paradermic observations of the middle portion of fresh leaves. Although anatomical characters were fairly homogeneous throughout the clade, twelve vegetative anatomical, phylogenetically informative characters were selected and coded for an analysis that was performed using an exhaustive search (implicit enumeration) implemented through TNT. The strict consensus of 2692 most parsimonious trees resulted in a poorly resolved polytomy, which however recovers the Trichocentrum-clade with a monophyletic, strongly supported Cohniella nested within it with unifacial leaves and the presence of cellular inclusions in the epidermis as synapomorphies. We concluded that the anatomy characters alone are insufficient to assess the relationships amongst the genera of the Trichocentrum-clade. However, the two synapomorphies recovered for Cohniella strongly support its monophyly when these are analyzed in conjunction with other data sources (e.g., molecular and morphological characters). Rev. Biol. Trop. 61 (4): 1841-1858. Epub 2013 December 01.
\end{abstract}

Key words: cladistic analysis, leaf anatomy, Cohniella, Lophiaris, Lophiarella, Trichocentrum.

Oncidiinae es una subtribu neotropical de la familia Orchidaceae que incluye alrededor de 76 géneros y 1 600-1 700 especies (números modificados de Chase 2009). En esta subtribu se encuentran los géneros Cohniella Pfitzer (22 spp.), Lophiarella Szlachetko, Mytnik-Ejsmont \& Romowicz (3 spp., sensu Carnevali, Cetzal-Ix, Balam, Leopardi, \& Romero-González, 2013), Lophiaris Rafinesque (25 spp.) y Trichocentrum Poepping \& Endlicher (25 spp.), los cuales constituyen el clado-Trichocentrum. Actualmente, existen dos circunscripciones genéricas alternas para este clado; algunos autores reconocen un solo género usando una delimitación amplia para Trichocentrum (Williams, Chase, Fulcher \& Whitten, 2001; Sosa, Chase, Salazar, Whitten, \& Williams, 2001; Sandoval-Zapotitla \& Terrazas, 2001; Chase, 2009; Neubig et al., 2012), mientras otros autores dividen al clado en los cuatro géneros antes mencionados (Pupulin, 1995; Carnevali, Cetzal-Ix, Balam, 
\& Romero-González, 2010; Cetzal-Ix \& Carnevali, 2010; Szlachetko, Mytnik-Ejsmont, \& Romowicz, 2006; Carnevali et al., 2013).

Los integrantes del clado-Trichocentrum se caracterizan por tener un número bajo de cromosomas $(2 n=26-36)$ y por tener pseudobulbos unifoliados y cubiertos por vainas que carecen de limbo foliar y hojas carnosas (Chase, 2009). Por otro lado, en la circunscripción alterna, cada grupo se puede distinguir tanto por caracteres vegetativos como florales (ver clave taxonómica en Carnevali et al., 2010; Cetzal-Ix \& Carnevali, 2011; Carnevali et al., 2013). Los representantes del cladoTrichocentrum se distribuyen desde el Sur de Florida y el Norte de México hasta el Sur de Brasil y Norte de Argentina, incluyendo las Antillas mayores (Pupulin \& Carnevali, 2005; Carnevali et al., 2010; Cetzal-Ix \& Carnevali, 2010; Balam, 2011). Lophiarella es el único género con distribución restringida al estar confinado al Suroeste de México y Noroeste de Mesoamérica (Carnevali et al., 2013). Las especies de estos géneros crecen en tierras bajas tropicales, desde bosques caducifolios y bosques húmedos tropicales hasta matorrales espinosos; aunque también pueden encontrarse en bosques de pino-encino, desde el nivel del mar hasta los $1700 \mathrm{~m}$ de elevación.

Los estudios de anatomía comparativa que han incluido representantes del cladoTrichocentrum han sido los de Sandoval-Zapotitla (1999), Sandoval-Zapotitla \& Terrazas (2001) y Sandoval-Zapotitla, Terrazas \& Vallejo (2003). Los análisis fenéticos presentados por estos autores muestran en común que los integrantes del clado-Trichocentrum forman un grupo (Grupo I), mientras que el resto de Oncidiinae forma otro diferente (Grupo II). En el estudio de Sandoval-Zapotitla (1999) el grupo I se divide a su vez en los subgrupos A para Lophiaris y Lophiarella, B para Cohniella y C para Trichocentrum+Trichopilia tortilis Lindl.

También hay estudios anatómicos filogenéticos basado en caracteres anatómicos obtenidos de representantes del clado-Trichocentrum (Stern \& Carlsward, 2006; SandovalZapotitla, García-Cruz, Terrazas \& Villaseñor, 2010a). Stern \& Carlsward (2006) analizaron las relaciones filogenéticas para 40 especies de Oncidiinae empleando ocho caracteres anatómicos vegetativos y uno morfológico; todos los miembros de Oncidiinae quedaron dentro de un clado sin resolución explicado por la presencia de una hipodermis adaxial y abaxial. Estos autores concluyeron que los caracteres anatómicos por sí solos son insuficientes para evaluar las relaciones genéricas dentro de Oncidiinae y por otra parte, indicaron que Trichocentrum s.s. presenta características anatómicas únicas por carecer de fibras extravasculares, hipodermis y estégmatos en las hojas anfistomáticas. Por su parte, Sandoval-Zapotitla et al. (2010a) analizaron 57 representantes de Oncidiinae y 29 caracteres anatómicos foliares, junto con ocho caracteres morfológicos y dos regiones de ADN (ITS y matK); en sus árboles Oncidiinae aparece como monofilético (definido por dos caracteres homoplásicos) y constituido por nueve clados, uno de los cuales contiene a los representantes del clado-Trichocentrum (definido por las hojas anfistomáticas y la presencia de dos o más estratos de haces vasculares).

Algunos autores (Sibley \& Ahlquist, 1987; Scotland, Olmstead \& Bennett, 2003) han enfatizado que los datos morfo-anatómicos son no informativos por presentar altos niveles de homoplasia, generan baja resolución y soporte para los clados en los análisis filogenéticos. Pero otros autores emplean estos caracteres combinándolos con datos morfológicos y de secuencias del ADN, para dilucidar relaciones a nivel genérico en conjunción (SandovalZapotitla et al., 2010a; Noguera-Savelli \& Jáuregui, 2011). El objetivo de este estudio fue investigar el poder de resolución taxonómica y de informatividad filogenética de los caracteres anatómicos dentro del clado-Trichocentrum y de manera particular, dentro del género Cohniella. Estudios posteriores analizarán este juego de caracteres, en combinación con otros provenientes de fuentes diferentes (e.g., morfología, ultra-estructura y secuencias de ADN) para obtener la mayor resolución posible en un análisis de evidencia total, siempre y cuando los juegos de información sean congruentes. 


\section{MATERIALES Y MÉTODOS}

Caracterización anatómica: Los especímenes del material estudiado provinieron de plantas recolectadas en el campo y plantas cultivadas; adicionalmente, la información anatómica incluida para algunas de las especies provino de descripciones publicadas en Abreu \& Peña (1982), Astudillo \& Cabrera (1983) y Sandoval-Zapotitla \& Terrazas
(2001) (Cuadro 1). Muestras de cada taxón fueron depositadas en el Herbario CICY, del Centro de Investigación Científica de Yucatán, Mérida, México.

Se utilizaron hojas maduras de plantas vivas, de las cuales se tomaron fragmentos de la porción media de la hoja y se fijaron en FAA (formaldehido $5 \%$, ácido acético $5 \%$, agua $40 \%$ y etanol $50 \%$ ) (Sass, 1958). Los fragmentos fueron seccionados transversalmente

CUADRO 1

Lista de especies del clado-Trichocentrum y del grupo externo incluidos en este trabajo

TABLE 1

List of species of Trichocentrum-clade and outgroup included in this work

\begin{tabular}{|c|c|c|c|}
\hline Taxa & Recolector/herbario & Localidad & LP \\
\hline Cohniella ascendens (Lindl.) Christenson & W. Cetzal s.n. (CICY) & México, Yucatán & 1 \\
\hline Cohniella biorbicularis Balam \& Cetzal & G. Carnevali 7259 (CICY) & México, Veracruz & 1 \\
\hline Cohniella brachyphylla (Lindl.) Cetzal \& Carnevali & G. Carnevali 7310 (CICY) & México, Chiapas & 1 \\
\hline Cohniella cebolleta (Jacq.) Christenson & G. Carnevali 7222 (CICY) & Venezuela, Zulia & 1 \\
\hline Cohniella cepula (Hoffmans.) & G. Carnevali \& I. Ramírez 7367 (CICY) & Perú, Moyobambo & 1 \\
\hline \multicolumn{4}{|l|}{ Carnevali \& G.A. Romero } \\
\hline Cohniella helicantha (Kraenzl.) Cetzal \& Carnevali & G. Carnevali 7027 (CICY) & Panamá, Veraguas & 1 \\
\hline Cohniella lacera (Lindl.) Cetzal & G. Carnevali 7311 (CICY) & Panamá, Colón & 1 \\
\hline Cohniella leptotifolia Cetzal \& Carnevali & G. Carnevali \& M. Gómez Juárez 6803 (CICY) & México, Sonora & 1 \\
\hline Cohniella nuda (Bateman ex Lindl.) Christenson & G. Carnevali 7222 (CICY) & Venezuela, Zulia & 1 \\
\hline Cohniella pendula Carnevali \& Cetzal & G. Carnevali \& I. Ramírez 6897 (CICY) & México, Jalisco & 1 \\
\hline Cohniella yucatanensis Cetzal \& Carnevali & W. Cetzal 22 (CICY) & México, Yucatán & 1 \\
\hline Lophiarella flavovirens (L.O. Williams) & Leleu 185 (AMO) & México, Guerrero & 4 \\
\hline \multicolumn{4}{|l|}{ Carnevali \& Balam } \\
\hline Lophiarella microchila (Bateman ex Lindl.) & E. Hágsater $4286(\mathrm{AMO})$ & México, Chiapas & 4 \\
\hline \multicolumn{4}{|l|}{ Szlach. et al. } \\
\hline Lophiarella splendida (A. Rich ex Duch.) & & Origen hortícola & 4 \\
\hline \multicolumn{4}{|l|}{ Carnevali \& Cetzal } \\
\hline Lophiaris bicallosa (Lindl.) Braem & M. A. Soto 3236 (AMO) & México, Chiapas & 4 \\
\hline Lophiaris carthagenensis (Jacq.) Braem & G. Morillo s.n. & Venezuela, Aragua & 3 \\
\hline Lophiaris cavendishiana (Bateman) Braem & G. Salazar 4707 (AMO) & México, Chiapas & 4 \\
\hline Lophiaris lanceana (Lind1.) Braem & Casaudoumecq s.n. & Venezuela, Miranda & 3 \\
\hline Lophiaris lurida (Lindl.) Braem & R. Jiménez s.n. (AMO) & México, Veracruz & 4 \\
\hline $\begin{array}{l}\text { Lophiaris oerstedii (Rchb. f.) R. Jiménez, } \\
\text { Carnevali \& Dressler }\end{array}$ & W. Cetzal s.n. (CICY) & México, Campeche & 1 \\
\hline Lophiaris straminea (Bateman ex Lindl.) Braem & J. García 668 (AMO) & México, Veracruz & 4 \\
\hline Trichocentrum candidum Lindl. & G. Salazar 5123 (AMO) & México, Veracruz & 4 \\
\hline Trichocentrum hoegei Rchb. f. & M. A. Soto s.n. (AMO) & México, Oaxaca & 4 \\
\hline $\begin{array}{l}\text { Chelyorchis ampliata (Lindl.) Dressler \& } \\
\text { N.H. Williams }\end{array}$ & C. Lamas s.n. (AMO) & - & 4 \\
\hline Chelyorchis pardoi Carnevali \& G.A. Romero & G. Carnevali s.n. & Venezuela, Apure & 2 \\
\hline Grandiphyllum pulvinatum (Lindl.) Docha Neto & E. Hágsater 11794 (AMO) & Brasil, Río de Janeiro & 4 \\
\hline Trigonidium egertonianum Bateman ex Lindl. & W. Cetzal s.n. (CICY) & México, Quintana Roo & 1 \\
\hline
\end{tabular}

La información analizada proviene de varias fuentes: 1) material revisado de colecciones de este estudio. 2-4) Literatura publicada (LP): 2. Abreu \& Peña, 1982; 3. Astudillo \& Cabrera, 1983; 4. Sandozal-Zapotitla \& Terrazas, 2001. 
a mano. Las secciones fueron teñidas en azul de toluidina $(0.5 \%)$, se montaron en glicerina $(50 \%)$ y se sellaron con esmalte transparente comercial para uñas. Para el estudio epidérmico se colocaron porciones de hoja de $0.5 \mathrm{~cm}$ en hipoclorito de sodio comercial (3.75\%) durante tres horas, se lavaron repetidamente con agua destilada y se eliminó el resto del mesofilo con ayuda de un pincel en el microscopio estereoscópico. Las porciones de epidermis se tiñeron y se montaron en la forma antes mencionada. Todas las láminas preparadas fueron fotografiadas con un microscopio óptico Nikon Eclipse E 200 equipado con cámara fotográfica digital Evolution LC en el Laboratorio de Anatomía Vegetal "Antonio Fernández", de la Facultad de Agronomía de la Universidad Central de Venezuela (UCV), en Maracay, Venezuela. Por otro lado, se observaron con un microscopio óptico binocular Leica-DME para la descripción de los caracteres de los tejidos dérmico, fundamental y vascular, en el Laboratorio de Poliquetos de El Colegio de la Frontera Sur, Unidad Chetumal, México.

\section{Análisis filogenético anatómico}

Grupo interno: El grupo interno incluyó representantes de los géneros del
clado-Trichocentrum, 11 (50\%) especies de Cohniella, tres (100\%) de Lophiarella, siete (28\%) de Lophiaris y dos (8\%) de Trichocentrum (Cuadro 1).

Grupo externo: El grupo externo estuvo representado por géneros de Oncidiinae que en análisis filogenéticos (Sosa et al., 2001, Chase, Hanson, Albert, Whitten \& Williams, 2005, Chase, 2009, Carnevali et al., 2013) aparecen como géneros hermanos del clado-Trichocentrum, dos especies de Chelyorchis Dressler \& N.H. Williams y una de Grandiphyllum Docha Neto (Cuadro 1), los cuales previamente habían sido considerados como miembros de Oncidium Sw. (e.g., Garay \& Stacy, 1974). El análisis fue enraizado con Trigonidium egertonianum Bateman, un miembro de la subtribu Maxillariinae que junto con Oncidiinae está incluida en la tribu Cymbidieae (Chase, 2009).

Caracteres anatómicos: A partir del estudio de anatomía foliar y de la literatura revisada (Abreu \& Peña, 1982, Astudillo \& Cabrera, 1983, Sandoval-Zapotitla \& Terrazas, 2001) se seleccionaron 12 caracteres con sus respectivos estados de carácter binarios o multiestado y tratados como no ordenados (parsimonia de Fitch (Fitch, 1971)) (Cuadro 2) con los cuales

CUADRO 2

Caracteres anatómicos y estados de carácter para el análisis filogenético

TABLE 2

Anatomical characters and character states for the phylogenetic analysis

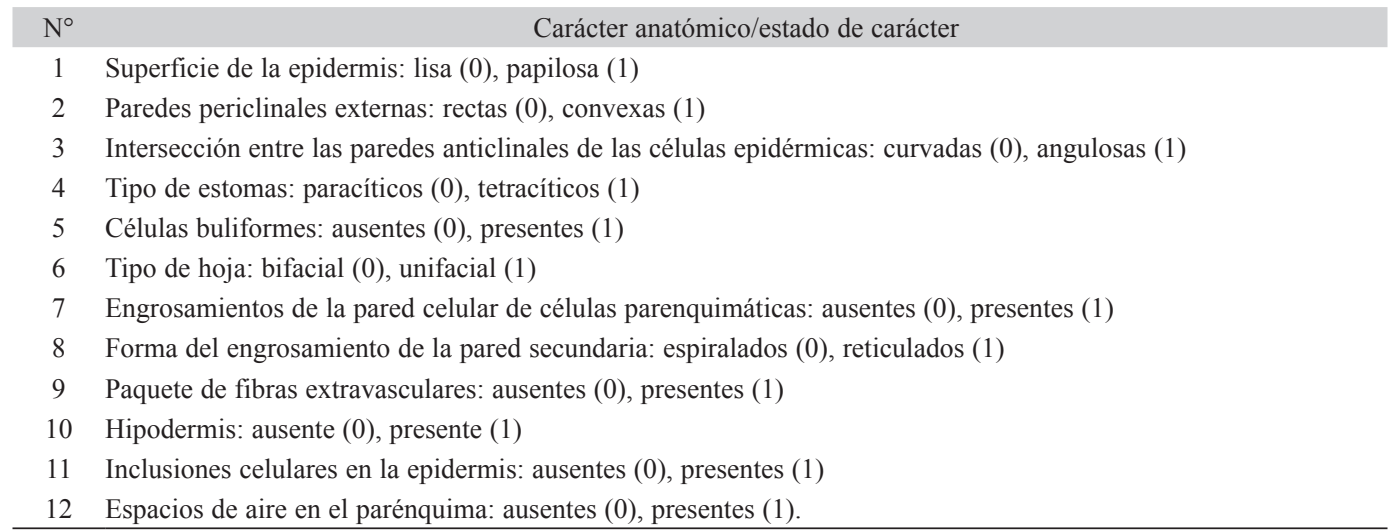


se construyó una matriz para el análisis filogenético (Apéndice).

Análisis filogenético: La reconstrucción filogenética se realizó a través de una búsqueda exhaustiva con el algoritmo de enumeración implícita implementado en el programa TNT (Goloboff, Farris \& Nixon, 2003), reteniendo 100000 árboles en la memoria. Se calculó el árbol de consenso estricto de los árboles más parsimoniosos para identificar los clados comunes a todos ellos. El soporte de los clados fue evaluado mediante un análisis de Bootstrap (BT) efectuado en Winclada (Nixon, 1999-2002), con 1000 iteraciones, con 10 repeticiones por búsqueda y un árbol retenido por iteración. Los porcentajes de 50-70 fueron considerados como bajo apoyo, de 71-85 como moderado apoyo y de $>85$ como fuerte apoyo (Kress, Prince \& Williams, 2002).

Para evitar confusión en el uso de los nombres genéricos que comienzan con la misma letra, estos se abreviaron de la siguiente manera: Cohniella (C), Chelyorchis (Ch), Lophiarella (La), Lophiaris (Ls), Trichocentrum (T) y Trigonidium (Tr).

\section{RESULTADOS}

Caracterización anatómica del sistema dérmico (Cuadro 3): EPIDERMIS: En sección transversal es uniestratificada, con paredes celulares periclinales externas rectas a convexas y gruesas. En los especímenes estudiados de Cohniella y del grupo externo la epidermis varía de lisa a papilosa (Fig. 1B); en las especies de Lophiarella, Lophiaris y Trichocentrum s.s. es papilosa (Fig. 1D).

NÚMERO DE PAPILAS POR CÉlULA EPIDÉRMICA: Varía de 1 a 13 por célula epidérmica. En Ch. ampliata, Cohniella, La. splendida y Ls. straminea, se observó una papila por célula (Fig. 1B). En las especies restantes las células pueden tener diferentes combinaciones de número de papilas por célula, por ejemplo en La. flavovirens, La. microchila y Lophiaris, el número va de 2 a 7 papilas por célula (Fig. 1D); en Trichocentrum de 2 a 11 papilas por células y en G. pulvinatum de 6 a 13 papilas por célula.

Forma DE CÉlUlAS EPIDÉRMICAS: En vista paradermal las células están dispuestas en hileras y presentan 4 a 8 lados con paredes anticlinales rectas y gruesas; en las especies de Cohniella, Trichocentrum s.s., Ls. oerstedii y $T r$. egertonianum las células epidérmicas tienen 4 a 6 lados, y las especies restantes presentan 4 a 8 lados.

INTERSECCIÓN ENTRE LAS PAREDES ANTICLINALES DE CÉlULAS EPIDÉRMiCAS: En la mayoría de las especies las células epidérmicas son angulosas, en $C$. helicantha, C. lacera y $T r$. egertonianum son curvadas.

Células buliformes: Únicamente presentes en $G$. pulvinatum y las dos especies de Chelyorchis.

TiPo De estomas: en especies de Cohniella, Lophiaris y del grupo externo se presentan estomas de tipo paracítico (Figs. 1E, G, H, L) o tetracítico (Figs. 1I-K), mientras que en Lophiarella y Trichocentrum s.s. son únicamente paracíticos.

Papilas en Células guardas: Presentes únicamente en C. yucatanensis, Ls. carthagenensis, Ls. oerstedii (Fig. 1K) y Ls. straminea.

Estriaciones EN ESTOMAS: Presentes únicamente en C. brachyphylla.

UbicACión DE ESTOMAS EN LA EPIDERMis: Hojas anfistomáticas en Chelyorchis, hipostomáticas en el resto de las especies, excepto en G. pulvinatum, en donde son de ambos tipos.

\section{Caracterización anatómica del sistema} fundamental (Cuadro 4): TIPO DE HOJA: Se observaron dos tipos de hojas de acuerdo a la disposición del parénquima, unifaciales en especies de Cohniella y bifaciales en las especies restantes (Fig. 2). 


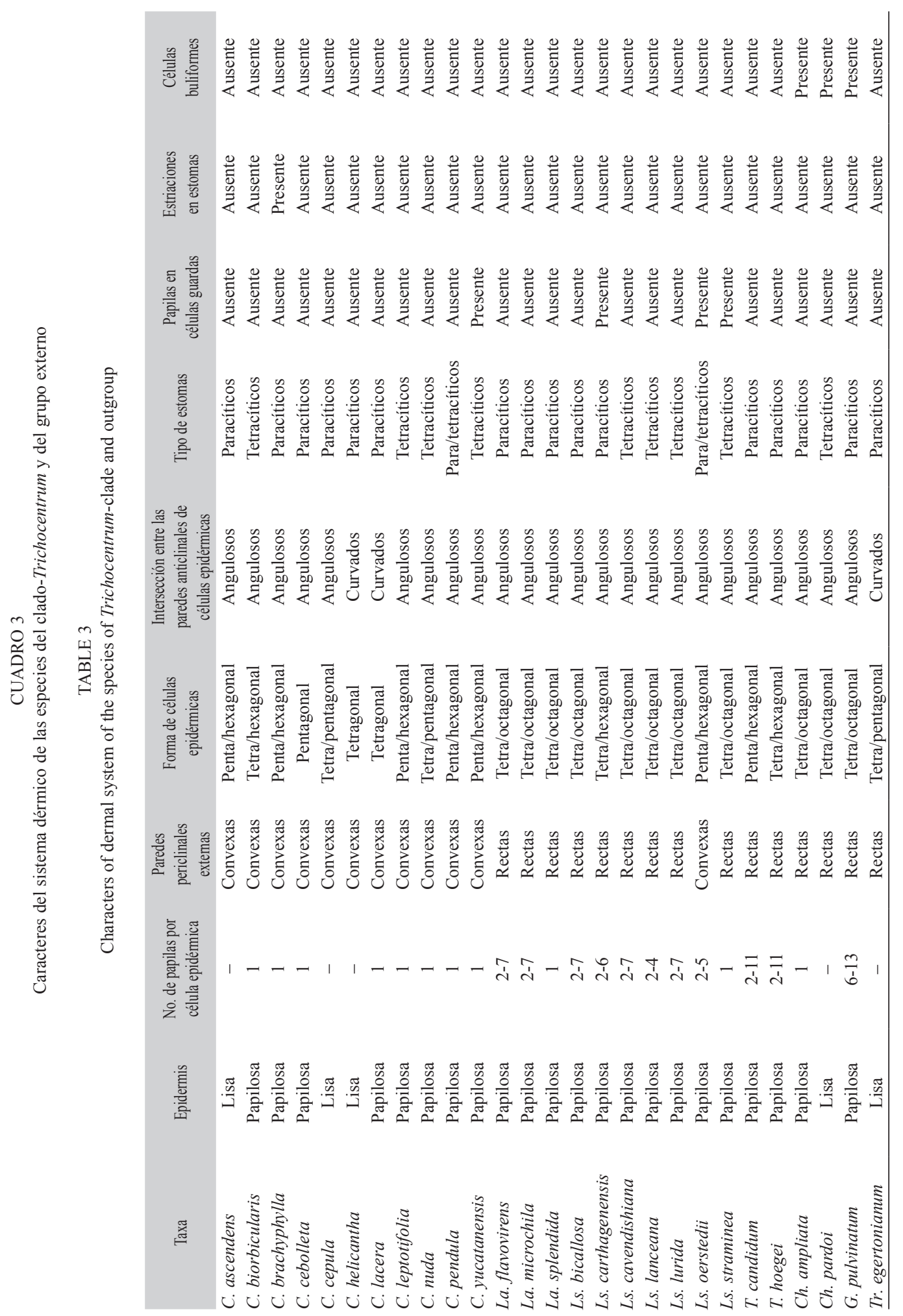



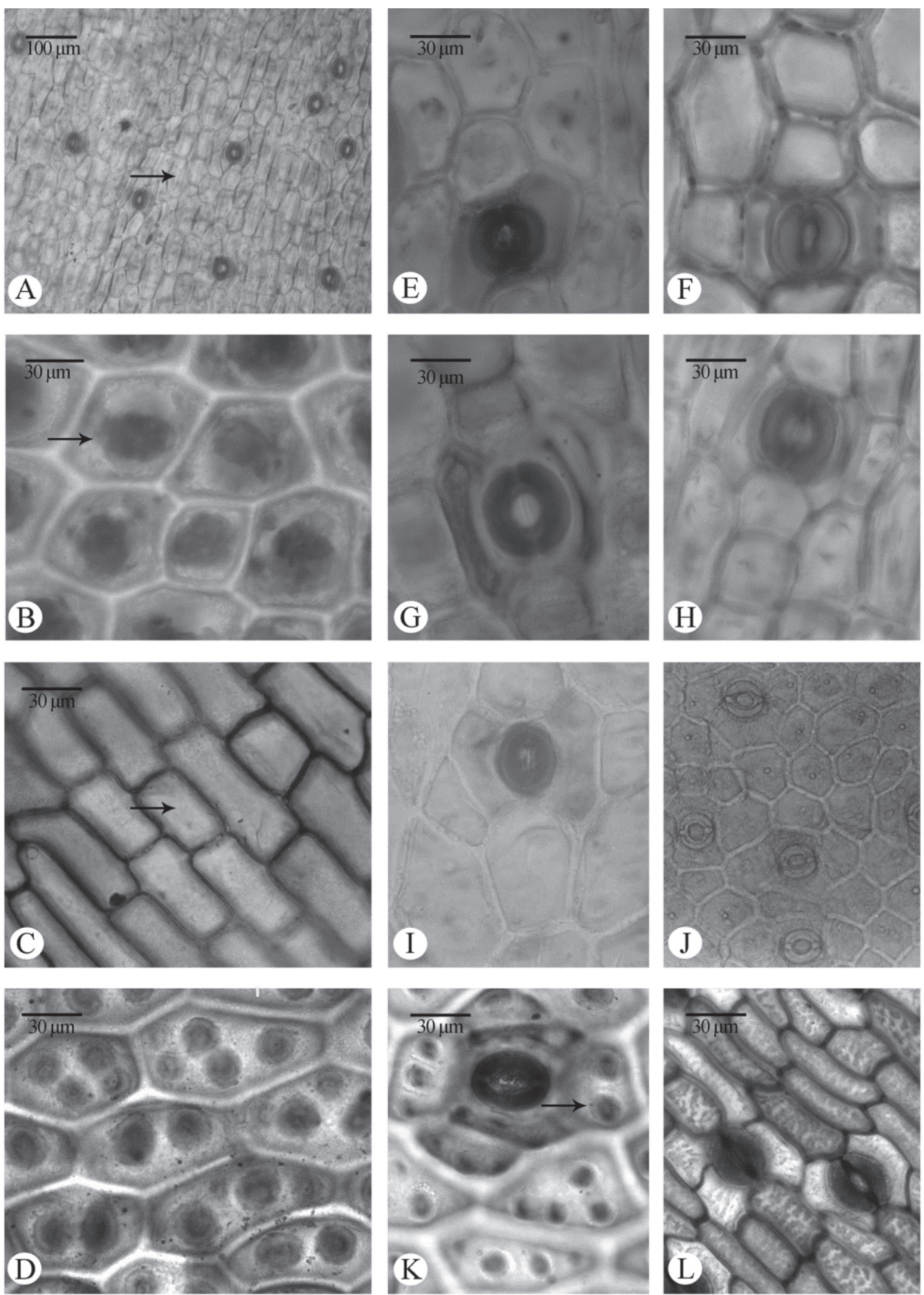

Fig. 1. Vistas paradérmicas de la epidermis foliar. (A, C) Células epidérmicas sin papilas. (B, D) Células epidérmicas con papilas. (E, G, H, L) Estomas paracíticos. (F, I. J, K) Estomas tetracíticos. (K) Papilas en células guardas, indicado con flecha. (A) Cohniella cepula. (B, F) Cohniella leptotifolia. (C, L) Trigonidium egertonianum. (D, K) Lophiaris oerstedii. (E) Cohniella ascendens. (G) Cohniella cebolleta. (H) Cohniella cepula. (I) Lophiaris lanceana. (J) Chelyorchis pardoi.

Fig. 1. Paradermal views of leaf epidermis. (A, C) Epidermal cells without papillae. (B, D) Epidermal cells with papillae. (E, G, H, L) Paracytic stomata. (F, I. J, K) Tetracytic stomata. (K) Papillae in guard cells, indicated by arrow. (A) Cohniella cepula. (B, F) Cohniella leptotifolia. (C, L) Trigonidium egertonianum. (D, K) Lophiaris oerstedii. (E) Cohniella ascendens. (G) Cohniella cebolleta. (H) Cohniella cepula. (I) Lophiaris lanceana. (J) Chelyorchis pardoi. 


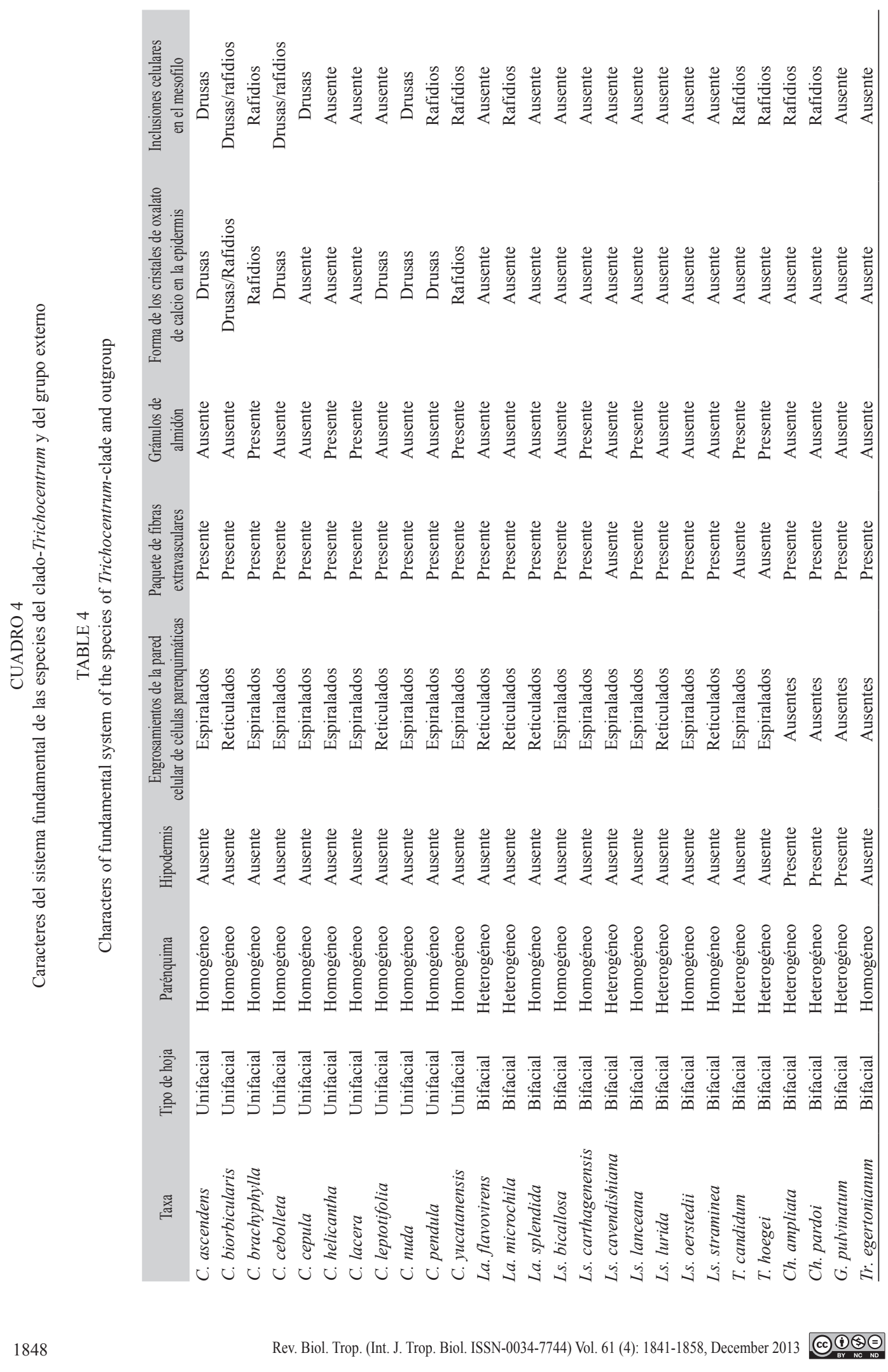




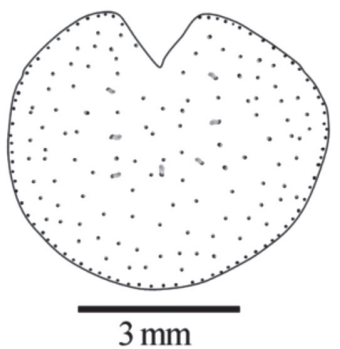

A

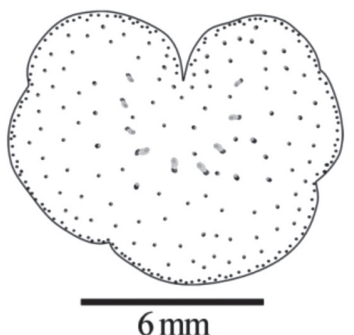

D

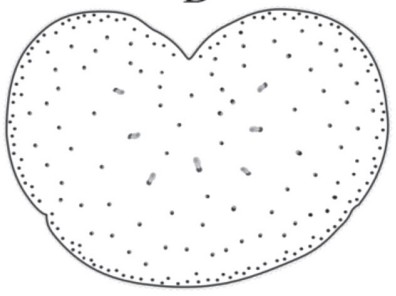

$3 \mathrm{~mm}$

G
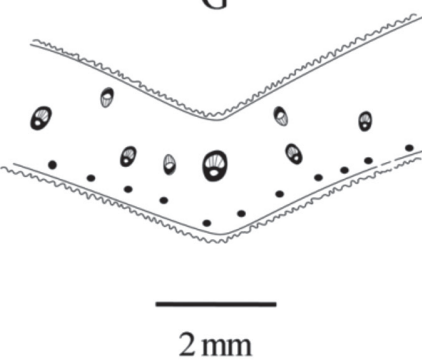

J

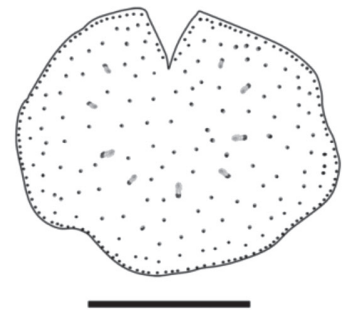

$6 \mathrm{~mm}$

B

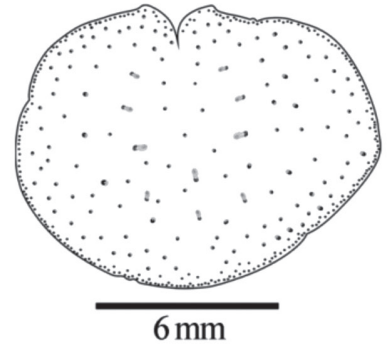

E

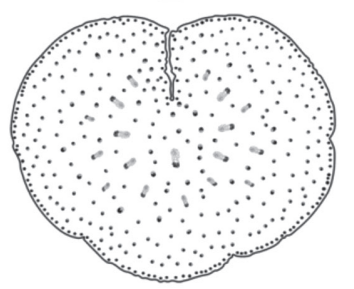

$\overline{2 \mathrm{~mm}}$

$\mathrm{H}$

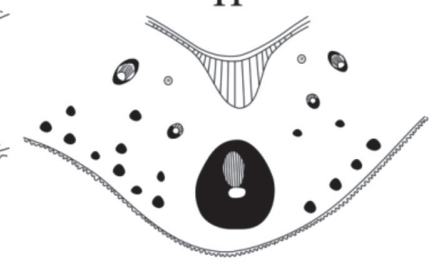

$2 \mathrm{~mm}$

K

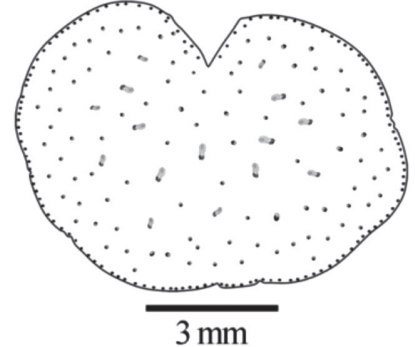

C
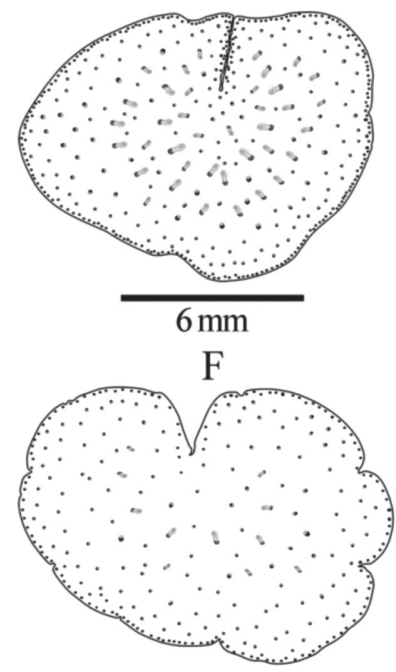

$2 \mathrm{~mm}$

I

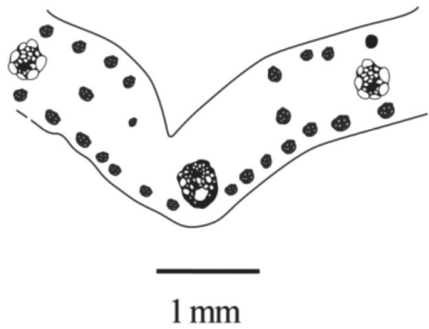

L

Fig. 2. Comparación de secciones transversales. (A) Cohniella ascendens. (B) Cohniella biorbicularis. (C) Cohniella cebolleta. (D) Cohniella cepula. (E) Cohniella helicantha. (F) Cohniella lacera. (G) Cohniella leptotifolia. (H) Cohniella nuda. (I) Cohniella pendula. (J) Lophiaris carthagenensis. (K) Chelyorchis pardoi. (L) Trigonidium egertonianum.

Fig. 2. Comparison of transverse sections. (A) Cohniella ascendens. (B) Cohniella biorbicularis. (C) Cohniella cebolleta . (D) Cohniella cepula. (E) Cohniella helicantha. (F) Cohniella lacera. (G) Cohniella leptotifolia. (H) Cohniella nuda. (I) Cohniella pendula. (J) Lophiaris carthagenensis. (K) Chelyorchis pardoi. (L) Trigonidium egertonianum. 
Parénquima: En las especies de Cohniella, La. splendida, Lophiaris (excepto en Ls. cavendishiana y Ls. lurida) y Tr. egertonianum es homogéneo con células de tamaño, disposición y morfología variables (Fig. 3A), en las especies restantes es heterogéneo.

Hipodermis: Presente únicamente en las dos especies de Chelyorchis y en G. pulvinatum.

ENGRosamientos DE LA PARED CELULAR DE CÉLULAS PARENQUimáticas: Ausente en las especies del grupo externo; reticulados en $C$. biorbicularis, C. leptotifolia (Fig. 3C), Lophiarella, Ls. lurida y Ls. straminea; espiralados en las especies restantes (Fig. 3B, D).

Paquete de fibras extravasculares: Ausentes únicamente en Ls. cavendishiana y Trichocentrum s.s.

Gránulos de Almidón: Presentes únicamente en C. brachyphylla, C. helicantha, C. lacera, C. yucatanensis, Ls. carthagenensis, Ls. lanceana y Trichocentrum s.s.

Forma DE los CRISTAles de OXAlato DE CAlCiO EN LA EPIDERMIS: Ausentes en C. серula, C. helicantha, C. lacera, Lophiarella, Lophiaris, Trichocentrum y las especies del grupo externo; drusas en $C$. ascendens (Fig. 3E), C. cebolleta, C. leptotifolia, C. nuda y $C$. pendula; rafidios en $C$. brachyphylla y C. yucatanensis; ambos tipos de cristales en $C$. biorbicularis.

INCLUSIONES CELULARES EN EL MESOFILO: Ausentes en C. helicantha, C. lacera, C. leptotifolia, La. flavovirens, La. splendida, Lophiaris, G. pulvinatum y Tr. egertonianum; drusas en $C$. ascendens, $C$. cepula y $C$. nuda; rafidios en $C$. brachyphylla, Chelyorchis, La. microchila y Trichocentrum; ambos tipos de cristales en $C$. biorbicularis y $C$. cebolleta (Fig. 3F).

Caracterización anatómica del sistema vascular: En todas las especies los haces vasculares son de tipo colateral cerrado. En Cohniella los haces vasculares principales se disponen en uno o dos arcos centrales y en el mesofilo como haces secundarios dispersos (e.g., Cohniella leptotifolia, Fig. 4A-B). El resto de las especies estudiadas presenta una hilera central de haces vasculares principales con haces secundarios intercalados o dispersos en el mesofilo.

Análisis filogenético: La matriz de datos incluyó 12 caracteres anatómicos (Apéndice). En la búsqueda heurística se encontraron 2692 árboles más parsimoniosos de 23 pasos (L), con un índice de consistencia (CI) de 52 y un índice de retención (RI) de 84 . El árbol de consenso estricto recuperó a Grandiphyllum + Chelyorchis (BT $=89 \%$ ) como el grupo hermano del cladoTrichocentrum. El clado-Trichocentrum incluye a los representantes de Cohniella, Lophiarella, Lophiaris y Trichocentrum s.s., está sustentado por una sinapomorfía y un apoyo de $85 \%$ (Fig. 5); sus integrantes se agrupan en una politomía. Dentro de éste los representantes de Cohniella forman un clado que está sustentado por dos sinapomorfías y apoyo fuerte del BT (86\%). Los representantes del clado Cohniella constituyen una politomía y dentro de la cual un par de especies muestran relaciones de taxa hermanos, $C$. biorbicularis y $C$. leptotifolia $(\mathrm{BT}=85 \%)$.

\section{DISCUSIÓN}

Sandoval-Zapotitla (1999) y SandovalZapotitla \& Terrazas (2001) agruparon a las papilas en micropapilas $(5-9 \mu \mathrm{m}$ de longitud), macropapilas cuticulares $(10-34 \mu \mathrm{m})$ y macropapilas epidérmicas $(18-24 \mu \mathrm{m})$, sin embargo, no pudieron señalar que el tamaño de las papilas permitiera reconocer los grupos I y II de Oncidiinae en su análisis. Por otra parte, Sandoval-Zapotitla (1999) señaló la presencia de papilas en $C$. ascendens, contrario a lo encontrados en este estudio. Sandoval-Zapotitla et al. (2003) indicaron que la presencia de papilas en la epidermis facilita una mejor captación de luz por diferentes ángulos oblicuos. Además, pueden actuar en la regulación de la cantidad de luz incidente, evitando que se 

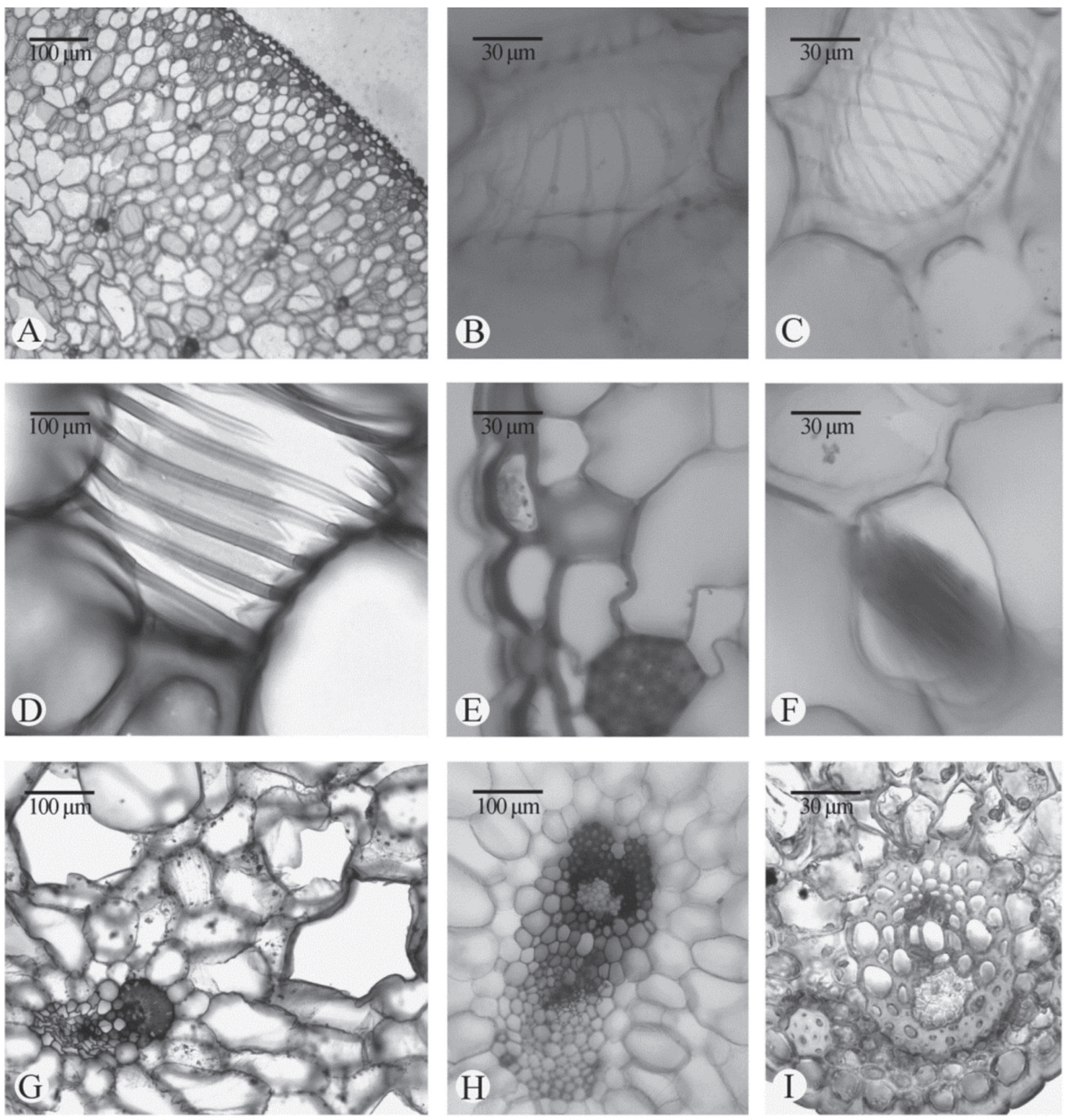

Fig. 3. Secciones transversales de hojas. (A) Cohniella nuda, parénquima homogéneo. (B y D) Células con engrosamientos espiralados. (B) Cohniella pendula. (C) Cohniella leptotifolia, células con engrosamientos reticulados. (D) Lophiaris oerstedii. (E) Cohniella ascendens, drusas en la epidermis. (F) Cohniella cebolleta, rafidios en el mesofilo. (G) Cohniella yucatanensis, espacios de aire. (H) Cohniella biorbicularis, haz vascular. (I) Trigonidium egertonianum, haz vascular central. Fig. 3. Cross sections of leaves. (A) Cohniella nuda, homogeneous parenchyma. (B y D) Cells with spiral thickenings. (B) Cohniella pendula . (C) Cohniella leptotifolia, cells with reticulated thickenings. (D) Lophiaris oerstedii. (E) Cohniella ascendens, drusen in epidermis. (F) Cohniella cebolleta, raphides in the mesophyll. (G) Cohniella yucatanensis, air spaces. (H) Cohniella biorbicularis, vascular bundle. (I) Trigonidium egertonianum, central vascular bundle.

calienten los tejidos subyacentes y se dañen los estomas (Lindorf, Parisca \& Rodríguez, 1991). De acuerdo con Williams (1974) el número de papilas por célula epidérmica es un carácter útil a nivel de subtribu y género en la clasificación de Oncidiinae. En este estudio, dentro del clado-Trichocentrum hay una relación entre la presencia de hojas teretes y la presencia de una sola papila por célula epidérmica, ya que ocho de 11 especies analizadas presentan esta condición. Sin embargo, parece haber también una relación entre la presencia de una papila por célula epidérmica en hojas teretes de especies que crecen en ambientes estacionalmente secos 


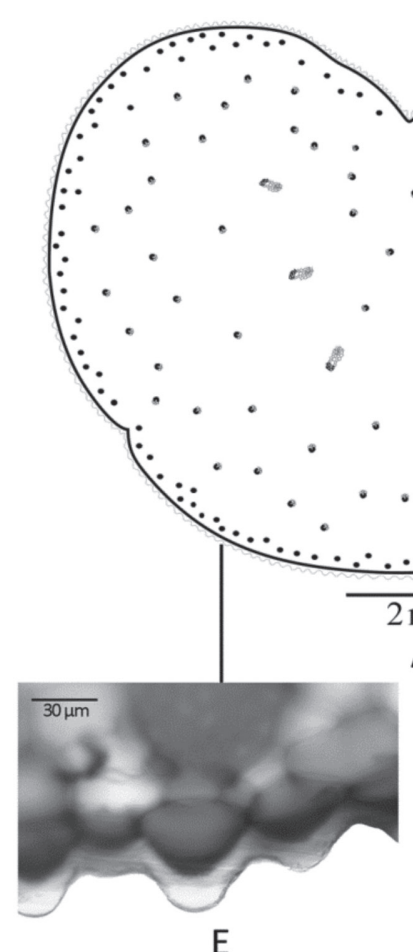

E

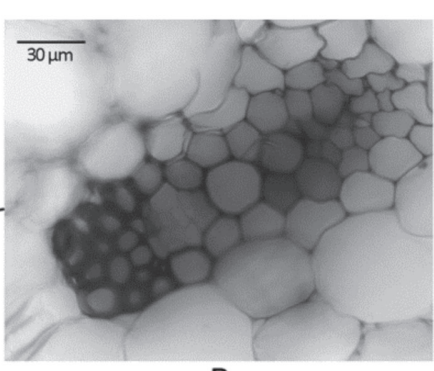

B

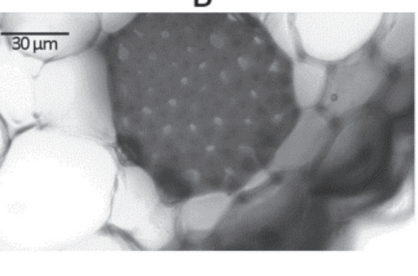

A

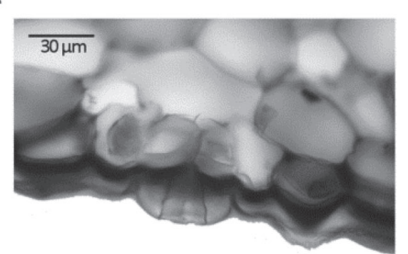

D

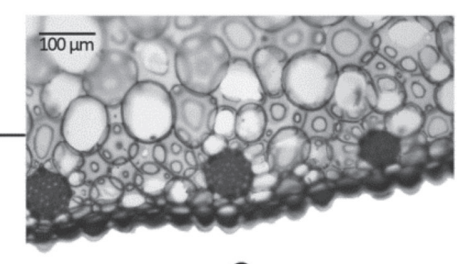

C

Fig. 4. Cohniella leptotifolia. (A) Sección transversal de la hoja. (B) Detalle del haz vascular. (C) Fibras extravasculares. (D) Estomas. (E) Papilas.

Fig. 4. Cohniella leptotifolia. (A) Transversal section of the leaf. (B) Detail of the vascular bundle. (C) extravascular fibers. (D) Stomata. (E) Papillae.

y expuestos a la alta radiación solar, mientras que las especies de ambientes húmedos y sombríos (e.g., C. ascendens, C. cepula y $C$. helicantha), poseen células epidérmicas carentes de papilas, lo que podría indicar que este no es un carácter que ha co-evolucionado con la forma de la hoja, y que quizás su evolución sea independiente en obediencia a factores ambientales. En este sentido, el patrón de hojas teretes con una papila por célula epidérmica fue también encontrado en algunas especies de Brassavola (Noguera-Savelli \& Jáuregui, 2011), Trimezia Salisb. ex Herb. (Iridaceae, Rudall 1993). Sin embargo, una sola papila por célula epidérmica no es un carácter exclusivo de las hojas teretes, este también se ha encontrado en algunas especies de hojas conduplicadas como Ch. ampliata, Dresslerella hirsutissima (C.
Schweinf.) Luer (Pridgeon 1982), La. splendida, y Ls. straminea.

Por otra parte, en la mayoría de los representantes de hojas conduplicadas el número de papilas es variable, en Lophiarella y Lophiaris se presentan de 2-7 papilas por célula y en Trichocentrum s.s. 2-11 papilas por célula. Es de destacar que la presencia de papilas se observó tanto en hojas conduplicadas como en hojas teretes, esto semejante a lo observado por Noguera-Savelli \& Jáuregui (2011) para Brassavola $\mathrm{R}$. Brown, otro género de orquídeas.

Stern \& Carlsward (2006) encontraron que en Oncidiinae el tipo básico de estoma fue tetracítico, sin especificar el tipo de estoma presente en cada especie; en este estudio, se observaron estomas paracíticos y tetracíticos, sin un patrón entre el tipo de estomas y las especies o 


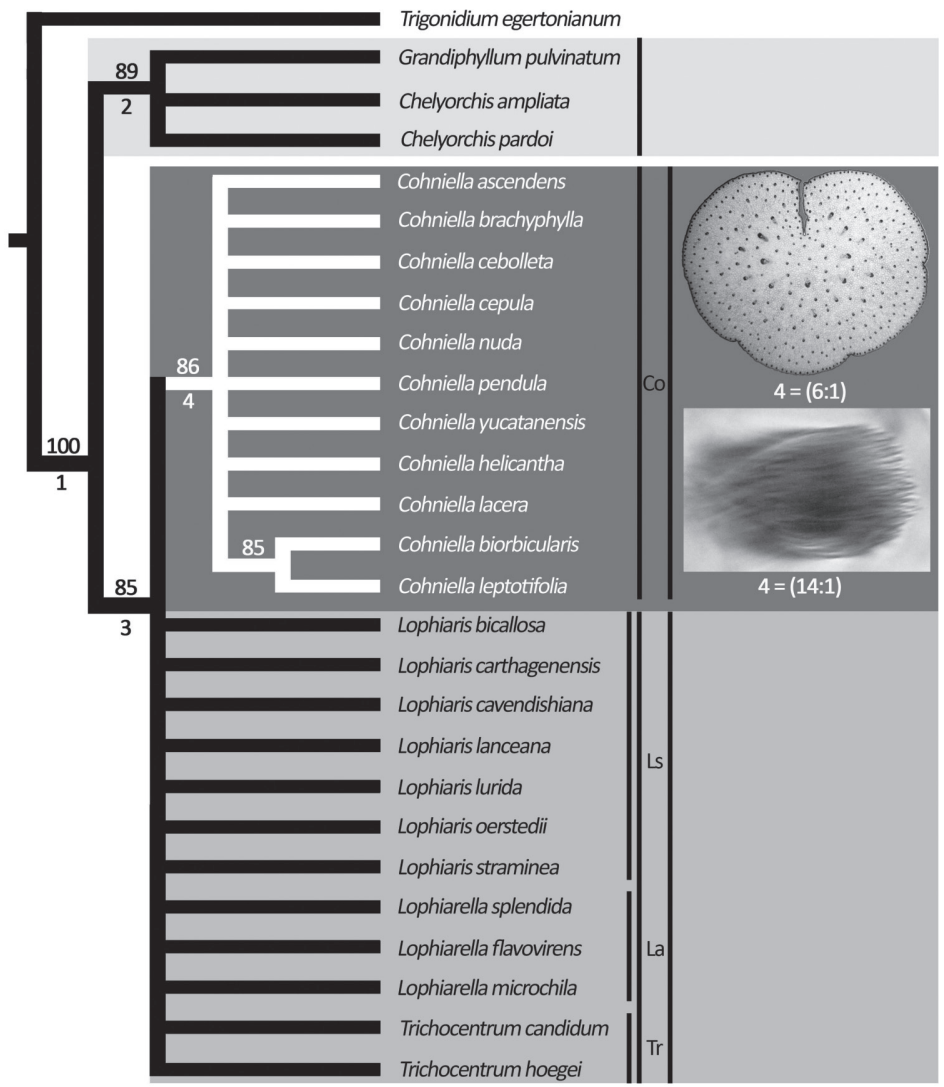

1. Epidermis papilosa (1:1); células epidérmicas angulosas $(3: 1)$.

2. Presencia de células buliformes $(5: 1)$; y de hipodermis $(10: 1)$.

3. Presencia de engrosamiento de la pared celular de células parenquimáticas $(7: 1)$.

4. Hoja unifacial (6:1); presencia de inclusiones celulares en la epidermis (11:1).

Fig. 5. Árbol de consenso estricto de 2692 árboles más parsimoniosos basado en caracteres anatómico foliares. L=23, $\mathrm{CI}=52, \mathrm{RI}=84$. Numero por encima de las ramas representan los porcentajes de bootstrap.

Fig. 5. Strict consensus tree of 2692 most parsimonious trees based on leaf anatomical characters. $L=23, I C=52, I R=84$. Numbers above the branches represent bootstrap percentages.

géneros. Otros caracteres, como presencia de papilas en las células o estriaciones en estomas, carecieron de utilidad taxonómica para las especies del clado-Trichocentrum incluidas en el estudio.

Sandoval-Zapotitla \& Terrazas (2001) indicaron que las células buliformes en la porción media de la hoja constituyen un carácter de valor taxonómico; los representantes del grupo I, clado-Trichocentrum, carecen de células buliformes, pero están presentes en las especies del grupo II. Estas células también están ausentes en los representantes Cohniella y Lophiaris incluidas en el presente estudio (clado-Trichocentrum) y ausentes en $C h$. ampliata, en Ch. pardoi y G. pulvinatum que son miembros del grupo II.

Oliveira \& Sajo (1999) señalaron que la constitución del mesófilo puede asociarse a la forma de la hoja, por lo general, las hojas teretes no presentan diferenciación entre parénquima en empalizada y esponjoso (homogéneo); 
en cambio en las hojas conduplicadas se puede presentar un parénquima diferenciado en empalizada y esponjoso (heterogéneo). Este patrón también fue encontrado por Noguera-Savelli \& Jáuregui (2011) en Brassavola. En el presente estudio, Cohniella, que tiene las hojas teretes, presentó parénquima homogéneo; en tanto, Lophiaris, Lophiarella y Trichocentrum s.s. con hojas conduplicadas presentaron parénquima heterogéneo, excepto La. splendida, Ls. bicallosa, Ls. carthagenensis, Ls. lanceana, Ls. oerstedii y Ls. straminea.

En algunas especies de orquídeas de la subtribu Pleurothallidinae (Pridgeon 1986, Scatena \& Nunes, 1996) y Laeliinae (NogueraSavelli \& Jáuregui, 2011) se observó que en ausencia de pseudobulbos y presencia de hojas carnosas, el mesofilo foliar posee células con engrosamientos espiralados, dichas células tienen por función almacenar agua y evitar el colapso de las mismas durante los períodos de sequía. Este tipo de células también están presentes en el mesofilo foliar de las especies que representaron al clado-Trichocentrum que poseen pseudobulbos reducidos y hojas carnosas, mientras que en las especies del grupo externo, que poseen pseudobulbos bien desarrollados y hojas coriáceas, no se observaron engrosamientos en las células del mesofilo.

Los caracteres observados en las especies del clado-Trichocentrum, indican que estas plantas poseen atributos xeromórficos, ya que la mayoría de ellas presentan papilas en la epidermis, las cuales pueden actuar en la regulación de la cantidad de luz incidente, evitando que se calienten los tejidos subyacentes y se dañen los estomas (Lindorf et al., 1991); mesofilo con células provistas de engrosamientos espiralados o reticulados que tienen por función almacenar agua y evitar el colapso de los tejidos durante los períodos de sequía, tal como se presenta en la subtribu Pleurothallidinae (Pridgeon, 1986; Scatena \& Nunes, 1996; Ely, Torres, Rada \& León, 2007); paquetes de fibras que le confieren a las hojas resistencia mecánica en caso de deshidratación de las plantas, brindándoles la capacidad de sobrevivir en hábitats xéricos (Oliveira \& Sajo, 1999;
Noguera-Savelli \& Jáuregui, 2011), y cristales cuya función no ha sido bien determinada, no obstante se vinculan con la regulación de los niveles de calcio, la protección contra la herbivoría y la detoxificación de metales pesados (Jáuregui-Zuñiga \& Moreno, 2004).

En general, la mayoría de los caracteres anatómico foliares evaluados en los representantes de los géneros del clado-Trichocentrum fueron similares, sin embargo, el carácter de hoja unifacial, es exclusivo de los representantes de Cohniella, lo que permite diferenciarlo a nivel taxonómico del resto de los géneros del clado-Trichocentrum.

La relaciones filogenéticas empleando caracteres morfológicos, de anatomía foliar y secuencias moleculares para representantes del clado-Trichocentrum ha sido evaluadas por Stern \& Carlsward (2006) y SandovalZapotitla et al. (2010a) al incluir algunas especies en análisis filogenéticos para Oncidiinae. Nuestro estudio representa el mayor muestreo dentro del clado-Trichocentrum al emplear caracteres anatómicos para 23 especies del grupo $(31.08 \%$ vs. $2.25 \%$ y $3.75 \%$, Stern \& Carlsward (2006), Sandoval-Zapotitla et al. (2010a), respectivamente).

El presente análisis filogenético recuperó a las tres especies del grupo externo (Chelyorchis + Grandiphyllum) en un clado con fuerte apoyo del BT y apoyado por la presencia de células buliformes e hipodermis. Estas tres especies no se incluyeron en el análisis filogenético de Sandoval-Zapotitla et al. (2010a); sin embargo, fueron reconocidas en el grupo II del clado Lophiaris (sensu Chase \& Palmer 1989) o Trichocentrum (sensu Williams et al., 2001) con base en los caracteres anteriores y otros anatómicos representados en un análisis fenético y del estudio comparativo de Sandoval-Zapotitla (1999) y Sandoval-Zapotitla \& Terrazas (2001), correspondientemente.

El clado-Trichocentrum fue recuperado en el presente estudio con un soporte moderado y sustentado por una sinapomorfía, la presencia de engrosamientos en la pared celular de células parenquimáticas. Algunos integrantes de este clado y el carácter que lo apoya 
como sinapomorfía, previamente fue incluido para las especies del grupo I de SandovalZapotitla (1999) o el grupo Trichocentrum en Sandoval-Zapotitla \& Terrazas (2001). La presencia de engrosamientos en la pared celular de células parenquimáticas también se presentó entre los integrantes del clado A en Sandoval-Zapotitla et al. (2010a) pero resulta ser una homoplasia que también se presenta en Tolumnia Raf. (clado I) y la subtribu Zygopetalinae (Sandoval-Zapotitla et al., 2010a). Los engrosamientos en la pared celular de células parenquimáticas han sido registrados en Pleurothallidinae (Pridgeon, 1986) y Brassavola R. Brown (Noguera-Savelli \& Jáuregui, 2011) donde se señala que almacenan agua para evitar el colapso de los tejidos durante los periodos de sequía. En las especies del clado-Trichocentrum los engrosamientos en la pared celular de células parenquimáticas quizás compensan la ausencia de una hipodermis que realiza el almacenamiento adicional de agua (Madisson, 1977; Roth, 1992). La presencia de hojas anfistomáticas fue reconocida entre los integrantes del clado-Trichocentrum en el estudio de Sandoval-Zapotitla et al. (2010a). Sin embargo, este carácter también se presenta en G. pulvinatum, especie del grupo externo que posee tanto hojas anfistomáticas como hipostomáticas (Sandoval-Zapotitla, 1999) pero especie no incluida en el análisis filogenético de Sandoval-Zapotitla et al. (2010a).

Dentro del clado-Trichocentrum los representantes de Lophiarella, Lophiaris y Trichocentrum s.s. de hojas conduplicadas se encuentran en la politomía basal. En SandovalZapotitla et al. (2010a) estos géneros estuviron representados por La. splendida ( $T$. splendidum) y $T$. pfavii, sin embargo, esta última estuvo más relacionada con $C$. brachyphylla (" $T$. cebolleta") por la presencia de una hoja con zona abaxial central convexa y los pseudobulbos reducidos. Por otro lado, tres representantes de Lophiarella y Lophiaris incluidas en el presente estudio aparecieron dentro del grupo I, subgrupo A del análisis fenético de SandovalZapotitla (1999), mientras que las dos especies de Trichocentrum s.s. quedaron incluidas en el grupo I, subgrupo C del mismo estudio.

El único clado recuperado dentro del clado-Trichocentrum en el presente análisis estuvo compuesto por las 11 especies de Cohniella de hojas teretes, tuvo como sinapomorfías una hoja unifacial y presencia de inclusiones celulares en la epidermis, y su soporte de BT fue fuerte. En Sandoval-Zapotitla et al. (2010a) este clado estuvo representado por $C$. brachyphylla ("T. cebolleta") y en Sandoval-Zapotitla (1999) por C. ascendens ("O. ascendens") y $C$. brachyphylla (“O. cebolleta"), las cuales quedaron agrupadas en el subgrupo $\mathrm{C}$ del grupo I con base a la presencia de una hoja terete. Las hojas teretes usualmente son unifaciales (Stern, Morris \& Judd, 1994), debido a que el parénquima no está diferenciado en parénquima de empalizada y esponjoso; por lo tanto, este carácter junto con la morfología terete de las hojas define a Cohniella dentro de Oncidiinae. Por otra parte, las inclusiones celulares encontradas en Cohniella pueden ser de tipo drusas o rafidios. En Oncidiinae únicamente se han descrito inclusiones celulares de tipo drusas en 10 especies de Oncidium y dos especies de Rhynchostele Rchb. f. por Sandoval-Zapotitla, Terrazas \& Villaseñor (2010b).

Los resultados de este estudio, basados solamente en 12 caracteres anatómicos, sugieren que estos caracteres no apoyan las relaciones genéricas dentro del clado-Trichocentrum, en oposición a los caracteres moleculares y morfológicos, los cuales, solos o en combinación, siempre permiten recuperar topologías donde los cuatro géneros del clado-Trichocentrum son monofiléticos. Sin embargo, la particular morfología del género Cohniella correlaciona claramente con varios caracteres anatómicos (hojas unifaciales y presencia de inclusiones celulares en la epidermis), cuyo análisis filogenético si permite recobrar al género como monofilético y con fuerte apoyo del BT.

\section{AGRADECIMIENTOS}

El primer autor agradece al CONACYT por la beca 162579 otorgada para estudios 
doctorales. La segunda autora agradece al ECOSUR por la beca otorgada para estudios posdoctorales. Norbelis Garcés (UCV) por la asistencia prestada en el laboratorio de anatomía. Luis Carrera Parra (ECOSUR) por las facilidades otorgadas para el fotografiado de láminas en el laboratorio de Poliquetos del ECOSUR. Silvia Hernández y José L. Tapia Muñoz (CICY) ayudaron en el procesamiento de los especímenes de respaldo. Sergio Salazar Vallejo y Luis Carrera Parra (ECOSUR) por sus valiosos comentarios y sugerencias que mejoraron el artículo. Asimismo, agradecemos a los cinco revisores anónimos y a los editores asociados por sus comentarios y sugerencias. GC y WCI agradecen al proyecto CONACYT 49980-Q otorgado al primero.

\section{RESUMEN}

El clado-Trichocentrum incluye los géneros Cohniella, Lophiarella, Lophiaris y Trichocentrum s.s. Estos géneros se distribuyen desde Florida y el Norte de México hasta el Sur de Brasil y Norte de Argentina, creciendo desde bosques caducifolios, bosques húmedos tropicales hasta matorrales espinosos y bosques de pino-encino, desde el nivel del mar hasta los $1700 \mathrm{~m}$. En este estudio se exploró el valor taxonómico y filogenético de la estructura anatómica de las hojas de 23 especies del cladoTrichocentrum, repartidos en 11 especies de Cohniella, tres de Lophiarella, siete de Lophiaris y dos de Trichocentrum s.s., y de otras cuatro especies incluidas como grupo externo. Se realizaron secciones transversales y observaciones paradérmicas de la porción media de hojas frescas para el estudio de los caracteres anatómicos. Doce caracteres anatómico foliares fueron seleccionados y codificados para el análisis filogenético que se realizó mediante el uso de una búsqueda exhaustiva (enumeración implícita) con el programa TNT. El consenso estricto de 2692 árboles más parsimoniosos dio lugar a una politomía que recupera dentro del clado-Trichocentrum a Cohniella como un clado monofilético fuertemente apoyado con sinapomorfías de las hojas unifaciales y la presencia de inclusiones celulares en la epidermis.

Palabras clave: análisis cladístico, anatomía foliar, Cohniella, Lophiarella, Lophiaris, Trichocentrum.

\section{REFERENCIAS}

Abreu, C. \& Peña, C. (1982). Estudio anatómico de hoja y tallo de orquideas que habitan en ambiente de bosque seco. (Tesis de licenciatura). Universidad Católica Andrés Bello, Caracas D.F., Venezuela.

Astudillo, M. A. \& Cabrera, P. G. (1983). Estudio anatómico de los órganos vegetativos de especies de orquideas pertenecientes al género Oncidium. (Tesis de licenciatura). Universidad Católica Andrés Bello, Caracas D.F., Venezuela.

Balam, R. (2011). Sistemática de Lophiaris Raf. (Orchidaceae). (Tesis de Doctorado). Centro de Investigación Científica de Yucatán, Mérida, México.

Carnevali, G., Cetzal-Ix, W., Balam, R. \& RomeroGonzález, G. A. (2010). A synopsis of Cohniella (Orchidaceae, Oncidiinae). Brittonia, 62(2), 153-177.

Carnevali, G., Cetzal-Ix, W., Balam, R., Leopardi, C. \& Romero-González, G. A. (2013). A combined evidence phylogenetic re-circumscription and a revision of Lophiarella (Orchidaceae: Oncidiinae). Systematic Botany, 38(1), 46-63.

Cetzal-Ix, W. \& Carnevali, G. (2010). A revision of Cohniella Pfitzer (Orchidaceae) in Mexico. The Journal of the Torrey Botanical Society, 137(2-3), 180-213.

Cetzal-Ix, W. \& Carnevali, G. (2011). A new species of Cohniella (Orchidaceae: Cymbideae, Oncidiinae) from Amazonian Venezuela. Novon: A Journal for Botanical Nomenclature, 21(2), 178-181.

Chase, M. W. (2009). Subtribe Oncidiinae. In A. M. Pridgeon, P. J. Cribb, M. W. Chase \& T. N. Rassmussen (Eds.), Genera Orchidacearum. 5. Epidendroideae. Part II. (p. 211-220). Oxford, Reino Unido: Oxford University.

Chase, M. W. \& Palmer, J. D. (1989). Chloroplast DNA systematics of liliod monocots: resources, feasibility, and an example from the Orchidaceae. American Journal of Botany, 76(12), 1720-1730.

Chase, M. W., Hanson, L., Albert, V. A., Whitten, W. M. \& Williams, N. H. (2005). Life history evolution and genome size in Subtribe Oncidiinae (Orchidaceae). Annals of Botany, 95(1), 191-199.

Ely, F., Torres, F., Rada, F. \& León, Y. (2007). Estudio morfo-anatómico de dos orquídeas de una selva nublada tropical. Interciencia, 32(6), 410-418.

Fitch, W. M. (1971). Toward defining the course of evolution: minimum change for a specific tree topology. Systematic Biology, 20(4), 406-416.

Garay, L. A. \& Stacy, J .E. (1974). Synopsis of the genus Oncidium. Bradea, 1(40), 398-428.

Goloboff, P., Farris, J. \& Nixon, K. (2003). T.N.T.: Tree Analysis Using New Technology. Program and documentation. Distribuido por los autores. Buenos Aires, Argentina.

Jáuregui-Zuñiga, D. \& Moreno, A. (2004). La biomineralización del oxalato de calcio en plantas: retos y potencial. $R E B, 23(1), 18-23$. 
Kress, W. J., Prince, L. M. \& Williams, K. J. (2002). The phylogeny and a new classification of the gingers (Zingiberaceae): evidence from molecular data. American Journal of Botany, 89(10), 1682-1696.

Lindorf, H., de Parisca, L. \& Rodríguez, P. (1991). Botánica: clasificación, estructura, reproducción. Caracas, D.F.: Ediciones de la Biblioteca, Universidad Central de Venezuela.

Madisson, M. (1977). Vascular epiphytes: their systematic occurrence and salient features. Selbyana, 2(1), 1-13.

Neubig, K. M., Whitten, W. M., Williams, N. H., Blanco, M. A., Endara, L., Burleigh, J. G., Silvera, K., Cushman, J. C. \& Chase, M. W. (2012). Generic recircumscriptions of Oncidiinae (Orchidaceae: Cymbidieae) based on maximum likelihood analysis of combined DNA datasets. Botanical Journal of the Linnean Society, 168(2), 117-228.

Nixon, K.C. (1999-2002). Winclada ver 1.0000. Ithaca, New York: published by the author.

Noguera-Savelli, E. \& Jáuregui, D. (2011). Anatomía foliar comparada y relaciones filogenéticas de 11 especies de Laeliinae con énfasis en Brassavola (Orchidaceae). Revista de Biología Tropical, 59(3), 1047-1059.

Oliveira, V. C. \& Sajo, M. G. (1999). Anatomía foliar de especies epífitas de Orchidaceae. Revista Brasileira de Botânica, 22(3), 365-374.

Pridgeon, A. M. (1982). Diagnostic anatomical characters in the Pleurothallidinae (Orchidaceae). American Journal of Botany, 69(6), 921-938.

Pridgeon, A. M. (1986). Anatomical adaptations in Orchidaceae. Lindleyana, 1(2), 90-101.

Pupulin, F. (1995). A revision of the genus Trichocentrum (Orchidaceae: Oncidiinae). Lindleyana, 10(3), 183-210.

Pupulin, F. \& Carnevali, G. (2005). Cohniella Pfitz. In F. Pupulin (Ed.), Vanishing Beauty: Native Costa Rican Orchids Vol. I. (pp. 141-147). San José, Costa Rica: University of Costa Rica Press.

Roth, I. (1992). Leaf structure: coastal vegetation and mangroves of Venezuela. Berlín, Alemania: Gebr. Borntraeger.

Rudall, P. (1993). Leaf anatomy and systematics of Mariceae (Iridaceae). Kew Bulletin, 48(1), 151-160.

Sandoval-Zapotitla, E. (1999). Anatomía foliar y análisis numérico del clado Lophiaris y géneros relacionados (Orchidaceae: Oncidiinae). (Tesis inédita de Maestría). Universidad Nacional Autónoma de México, D.F., México.

Sandoval-Zapotitla, E., García-Cruz, J., Terrazas, T. \& Villaseñor, J. L. (2010a). Relaciones filogenéticas de la subtribu Oncidiinae (Orchidaceae) inferidas a partir de caracteres estructurales y secuencias de
ADN (ITS y matK): un enfoque combinado. Revista Mexicana de Biodiversidad, 81(2), 263-279.

Sandoval-Zapotitla, E. \& Terrazas, T. (2001). Leaf anatomy of 16 taxa of the Trichocentrum clade (Orchidaceae: Oncidiinae). Lindleyana, 16(2), 81-93.

Sandoval-Zapotitla, E., Terrazas, T. \& Villaseñor, J. L. (2010b). Diversidad de inclusiones minerales en la subtribu Oncidiinae (Orchidaceae). Revista de Biología Tropical, 58(2), 733-755.

Sandoval-Zapotitla, E., Terrazas, T. \& Vallejo, A. (2003). Análisis fenético de caracteres anatómicos-foliares de Trichocentrum y géneros relacionados (Orchidaceae, Oncidiinae). Lankesteriana, 7(2), 51-53.

Sass, J. (1958). Botanical microtechnique. Iowa, USA: Iowa State College Press.

Scatena, V. \& Nunes, A. (1996). Anatomía de Pleurothallis rupestris Lindl. (Orchidaceae) de dos campos rupestres de Brasil. Boletim de Botânica, Universidade de São Paulo, 15, 35-43.

Scotland, R. W., Olmstead, R. G. \& Bennett, J. R. (2003). Phylogeny reconstruction: the role of morphology. Systematic Biology, 52(4), 539-548.

Sibley, C. G. \& Ahlquist, J. E. (1987). DNA hybridization evidence of hominid phylogeny: results from an expanded data set. Journal of Molecular Evolution, 26(1-2), 99-121.

Sosa, V. M., Chase, M. W., Salazar, G., Whitten, M. \& Williams, N. H. (2001). Phylogenetic position of Dignathe (Orchidaceae: Oncidiinae): evidence from nuclear ITS ribosomal DNA sequences. Lindleyana, 16(2), 94-101.

Stern, W. L. \& Carlsward, B. S. (2006). Comparative vegetative anatomy and systematics of the Oncidiinae (Maxillarieae, Orchidaceae). Botanical Journal of the Linnean Society, 152(1), 91-107.

Stern, W. L., Morris, M. W. \& Judd, M. S. (1994). Anatomy of the thick leaves in Dendrobium section Rhyzobium (Orchidaceae). International Journal of Plant Sciences, 155(6), 716-729.

Szlachetko, D. L., Mytnik-Ejsmont, J. \& Romowicz, A. (2006). Genera et Species Orchidalium. 14. Oncidieae. Polish Botanical Journal, 51(1), 53-55.

Williams, N. H. (1974). The value of plant anatomy in orchid taxonomy. In M. Ospina (Ed.), Proceedings of the seventh World Orchid Conference (pp. 281-298). Medellin, Colombia.

Williams, N. H., Chase, M. W., Fulcher, T. \& Whitten, W. M. (2001). Molecular systematics of the Oncidiinae based on evidence from four DNA sequence regions: expanded circumscriptions of Cyrtochilum, Erycina, Otoglossum, Trichocentrum, and a new genus (Orchidaceae). Lindleyana, 16(2), 113-139. 
APÉNDICE

Matriz para el análisis filogenético

APPENDIX

Matrix for phylogenetic analysis

\begin{tabular}{|c|c|c|c|c|c|c|c|c|c|c|c|c|}
\hline Taxones & 1 & 2 & 3 & 4 & 5 & 6 & 7 & 8 & 9 & 10 & 11 & 12 \\
\hline Trigonidium egertonianum & 0 & 0 & 0 & 0 & 0 & 0 & 0 & $?$ & 0 & 0 & 0 & $?$ \\
\hline Grandiphyllum pulvinatum & 1 & 0 & 1 & 0 & 1 & 0 & 0 & $?$ & 0 & 1 & 0 & 0 \\
\hline Chelyorchis ampliata & 1 & 0 & 1 & 0 & 1 & 0 & 0 & $?$ & 0 & 1 & 0 & 1 \\
\hline Chelyorchis pardoi & 0 & 0 & 1 & 1 & 1 & 0 & 0 & $?$ & 0 & 1 & 0 & 1 \\
\hline Cohniella ascendens & 0 & 1 & 1 & 0 & 0 & 1 & 1 & 0 & 0 & 0 & 1 & 1 \\
\hline Cohniella biorbicularis & 1 & 1 & 1 & 1 & 0 & 1 & 1 & 1 & 0 & 0 & 1 & 1 \\
\hline Cohniella brachyphylla & 1 & 1 & 1 & 0 & 0 & 1 & 1 & 0 & 0 & 0 & 1 & 1 \\
\hline Cohniella cebolleta & 1 & 1 & 1 & 0 & 0 & 1 & 1 & 0 & 0 & 0 & 1 & 1 \\
\hline Cohniella cepula & 0 & 1 & 1 & 0 & 0 & 1 & 1 & 0 & 0 & 0 & 0 & 1 \\
\hline Cohniella helicantha & 0 & 1 & 0 & 0 & 0 & 1 & 1 & 0 & 0 & 0 & 0 & 1 \\
\hline Cohniella lacera & 1 & 1 & 0 & 0 & 0 & 1 & 1 & 0 & 0 & 0 & 0 & 1 \\
\hline Cohniella leptotifolia & 1 & 1 & 1 & 1 & 0 & 1 & 1 & 1 & 0 & 0 & 1 & 1 \\
\hline Cohniella nuda & 1 & 1 & 1 & 1 & 0 & 1 & 1 & 0 & 0 & 0 & 1 & 1 \\
\hline Cohniella pendula & 1 & 1 & 1 & 0,1 & 0 & 1 & 1 & 0 & 0 & 0 & 1 & 1 \\
\hline Cohniella yucatanensis & 1 & 1 & 1 & 1 & 0 & 1 & 1 & 0 & 0 & 0 & 1 & 1 \\
\hline Lophiaris bicallosa & 1 & 0 & 1 & 0 & 0 & 0 & 1 & 0 & 0 & 0 & 0 & 0 \\
\hline Lophiaris carthagenensis & 1 & 0 & 1 & 0 & 0 & 0 & 1 & 0 & 0 & 0 & 0 & 0 \\
\hline Lophiaris cavendishiana & 1 & 0 & 1 & 1 & 0 & 0 & 1 & 0 & 1 & 0 & 0 & 0 \\
\hline Lophiaris lanceana & 1 & 0 & 1 & 1 & 0 & 0 & 1 & 0 & 0 & 0 & 0 & 0 \\
\hline Lophiaris lurida & 1 & 0 & 1 & 1 & 0 & 0 & 1 & 1 & 0 & 0 & 0 & 0 \\
\hline Lophiaris oerstedii & 1 & 1 & 1 & 0,1 & 0 & 0 & 1 & 0 & 0 & 0 & 0 & 0 \\
\hline Lophiaris straminea & 1 & 0 & 1 & 1 & 0 & 0 & 1 & 1 & 0 & 0 & 0 & 0 \\
\hline Lophiarella flavovirens & 1 & 0 & 1 & 0 & 0 & 0 & 1 & 1 & 0 & 0 & 0 & 0 \\
\hline Lophiarella microchila & 1 & 0 & 1 & 0 & 0 & 0 & 1 & 1 & 0 & 0 & 0 & 0 \\
\hline Lophiarella splendida & 1 & 0 & 1 & 0 & 0 & 0 & 1 & 1 & 0 & 0 & 0 & 0 \\
\hline Trichocentrum candidum & 1 & 0 & 1 & 0 & 0 & 0 & 1 & 0 & 1 & 0 & 0 & 0 \\
\hline Trichocentrum hoegei & 1 & 0 & 1 & 0 & 0 & 0 & 1 & 0 & 1 & 0 & 0 & 0 \\
\hline
\end{tabular}

